TARBIYATUNA: Kajian Pendidikan Islam

Volume 3 Nomor 2 Tahun 2019

Print ISSN : 2597-4807

Online ISSN : 2622-1942

\title{
STRATEGI GURU PENDIDIKAN AGAMA ISLAM (PAI) \\ DALAM MENANAMKAN NILAI-NILAI KARAKTER PADA SISWA (STUDI MULTI KASUS DI SDI RAUDLATUL JANNAH SIDOARJO DAN SDIT GHILMANI SURABAYA)
}

\author{
Afifah ${ }^{1}$, Imam Mashuri ${ }^{2}$ \\ ${ }^{1}$ Fakultas Tarbiyah, Sekolah Tinggi Agama Islam Taruna Surabaya \\ 2 Fakultas Tarbiyah, Institut Agama Islam Ibrahimy Genteng Banyuwangi \\ e-mail: ${ }^{1}$ afifahsyahira@gmail.com , ${ }^{2}$ mashuri5758.aba@gmail.com
}

\begin{abstract}
The purpose of this study first, to describe the character values implanted by teachers of PAI on students in SDI Raudlatul Jannah Sidoarjo and SDIT Ghilmani Surabaya. Second, describe the strategy of PAI teachers in instilling the character values of students in SDI Raudlatul Jannah Sidoarjo and SDIT Ghilmani Surabaya. Third, describe the process of internalization of character values on students in SDI Raudlatul Jannah Sidoarjo and SDIT Ghilmani Surabaya. This research uses qualitative approach with descriptive technique of descriptive informant. Data collection techniques with participant observation, in-depth interviews, and documentation analysis. The results of this study conclude that in the inculcation of the values of character education in the students the teacher has a special strategy by applying his role as educator, lecturer, curriculum developer, reformer, model and role model in integrating character values into the whole subjects, day, school programs, and building cooperation between schools with parents.
\end{abstract}

Keywords: Strategy, Islamic Religious Education Teachers, Character

\begin{tabular}{|c|c|c|}
\hline Accepted: & Reviewed: & Publised: \\
Juli 22 2019 & Agustus 25 2019 & September 30 2019 \\
\hline
\end{tabular}

\section{A. Pendahuluan}

Pembelajaran pada dasarnya merupakan upaya untuk mengarahkan anak didik ke dalam proses belajar sehingga mereka dapat memperoleh tujuan belajar sesuai dengan apa yang diharapkan. Pembelajaran hendaknya memperhatikan kondisi individu anak karena merekalah yang akan belajar. Anak didik merupakan individu yang berbeda satu sama lain, memiliki keunikan masing-masing yang tidak sama dengan orang lain. Oleh karena itu pembelajaran hendaknya memperhatikan perbedaan-perbedaan individual anak tersebut, sehingga

This work is licensed under Creative Commons AttributionNon Commercial 4.0 International License Available iaiibrahimy.ac.id 
pembelajaran benar-benar dapat merubah kondisi anak dari yang tidak mengerti menjadi mengerti, dari yang tidak paham menjadi paham serta dari yang berperilaku kurang baik menjadi baik. Kenyataannya anak seperti ini, selama ini kurang mendapat perhatian di kalangan pendidik.

Dalam pendidikan diperlukan peran guru sebagai pendidik dan pengajar yang profesional, materi yang relevan dengan kebutuhan, metode yang tepat untuk mencapai tujuan, evaluasi sebagai alat mengukur kemampuan serta sarana dan prasarana untuk mendukung kegiatan pembelajaran. Begitupun dengan siswa dan lingkungannya sangat menentukan keberhasilan pendidikan. Guru juga harus pandai memilih metode yang sesuai untuk menyajikan materi tersebut. Oleh karena itu agar pendidikan dan pengajaran yang dipaparkan guru kepada anak didik memperoleh respon positif pula (terjadi keseimbangan antara ranah kognitif, afektif dan psikomotorik) maka hendaklah guru dapat mengaplikasikan metode pengajarannya semenarik mungkin.

Penelitian ini dilatar belakangi oleh metode yang digunakan di sekolah dirasakan masih kurang menciptakan suasana kondusif dan menyenangkan bagi siswa untuk dapat mempelajari serta mencerna isi atau materi pelajaran. Hal ini membuat siswa kurang kosentrasi bahkan menjadi malas dalam mengikuti mata pelajaran di sekolah. Guru mempunyai kedudukan khusus dalam masyarakat bahkan sejak masa lalu. Sepak terjang serta lagak lagunya banyak mewarnai kehidupan, baik sekarang maupun di masa yang akan datang. Mereka sering tampil di panggung pembicaraan orang banyak, dan menjadi berita hangat media masa (Permadi, 2010:1). Dalam masyarakat juga dikenal pameo: "guru harus (dapat) digugu dan ditiru" dan "guru kencing berdiri, murid kencing berlari", dalam pameo tersebut tersirat pandangan serta harapan tertentu dari masyarakat terhadap guru. Memang tidak dinyatakan siapa yang harus "menggugu" dan menirunya, apakah terbatas pada siswanya atau berlaku juga untuk seluruh masyarakat. Namun kenyataan menunjukkan dari ketentuan atau kaidah masyarakat, manakala guru itu menyimpang dari apa yang diharapkan masyarakat dari padanya. 
Masyarakat langsung memberikan suara sumbang kepadanya, bahkan sering pula suara sumbang itu di tunjukkan kepada seluruh jajaran guru.

Kenakalan anak yang kini merajalela di beberapa tempat, sering pula tanggung jawabnya di tudingkan kepada guru sepenuhnya. Dalam kedudukan seperti itu sebenarnya guru tidak lagi hanya dipandang sebagai pengajar di kelas, namun mereka diharapkan pula tampil sebagai pendidik, bukan saja terhadap anak didiknya di kelas melainkan juga sebagai pendidik di masyarakat yang seyogyanya memberikan teladan yang baik kepada seluruh masyarakat. Dalam kedudukan ini mereka kembali tampil sebagai orang yang harus digugu dan ditiru, bahkan oleh seluruh masyarakat, manakala seorang guru berhasil atau dianggap berhasil memenuhi harapan masyarakat itu, ia pun mendapatkan tempat khusus di mata masyarakat. Ia menjadi tempat bertanya, tempat terhormat, dan berbagai jabatan serta kedudukan disodorkan kepadanya. Guru seperti itulah yang dilukiskan dalam pameo "Guru ratu wong atuwo karo" yang mendapat penghormatan bahkan melebihi raja (Permadi dkk, 2010:1).

Dalam pembelajaran di kelas, guru berhadapan dengan sejumlah siswa yang semuanya ingin diperhatikan. Siswa akan berkembang secara optimal melalui perhatian guru yang positif, sebaliknya perhatian yang negatif akan menghambat perkembangan siswa. Mereka senang jika mendapat pujian dari guru, dan merasa kecewa jika kurang diperhatikan atau diabaikan (Mulyasa, 2009:22). Tugas guru tidak hanya menyampaikan informasi kepada siswa, tetapi harus dilatih menjadi fasilitator yang bertugas memberikan kemudahan belajar kepada seluruh siswa, agar mereka dapat belajar dalam suasana yang menyenangkan, gembira, penuh semangat, tidak cemas dan berani mengemukakan pendapat secara terbuka merupakan modal dasar bagi peserta didik untuk tumbuh dan berkembang menjadi manusia yang siap beradaptasi, menghadapi berbagai kemungkinan, dan memasuki era globalisasi yang sarat tantangan dan persaingan (Mulyasa, 2007:162-163). 
Akhir-akhir ini pendidikan karakter tengah menjadi topik perbincangan yang menarik. Entah di sekolah-sekolah, forum seminar, diskusi di kampuskampus maupun diberbagai media elektronik maupun media cetak. Pendidikan karakter, saat ini dan mungkin beberapa tahun ke depan sedang "ngetrend" dan "booming" itu tidak lepas dari gemparnya sosialisasi yang dilakukan kementrian pendidikan dan kebudayaan, sebagai upaya memperbaiki karakter generasi muda pada khususnya dan bangsa ini pada umumnya. Dampak globalisasi yang terjadi saat ini membawa masyarakat Indonesia melupakan pendidikan karakter bangsa. Padahal, pendidikan karakter merupakan suatu pondasi bangsa yang sangat penting dan perlu ditanamkan sejak dini kepada anak-anak (Muslich, 2013:1).

Di Indonesia pelaksanaan pendidikan karakter saat ini memang dirasakan mendesak. Gambaran situasi masyarakat bahkan situasi dunia pendidikan di Indonesia menjadi motivasi pokok pendidikan karakter di Indonesia. Pendidikan karakter di Indonesia dirasakan amat perlu pengembangannya bila mengingat makin meningkatnya tawuran antar pelajar, serta bentuk-bentuk kenakalan remaja lainnya terutama di kota-kota besar, pemerasan/kekerasan (bullying), kecenderungan dominasi senior terhadap yunior, penggunaan narkoba dan lainlain (Samani \& Hariyanto, 2011:2). Adapun hambatan yang berasal dari siswa yaitu siswa masih belum bisa saling menghormati dan berbagi apa yang dimiliki terhadap teman sepermainan terutama masih belum adanya pembiasaan siswa mengaplikasikan nilai-nilai karakter baik di sekolah, di rumah maupun di masyarakat (Observasi awal, 15 Juli 2016). Di lingkungan keluarga yang mestinya sebagai tempat pembelajaran bahasa ibu, orangtua kurang memberikan pembiasaan kepada anak untuk mengaplikasikan nilai-nilai karakter yang harus dimiliki.

Menurut Garin Nugroho yang dikutip oleh Masnur Muslich, mengatakan bahwa sampai saat ini dunia pendidikan di Indonesia dinilai belum mendorong pembangunan karakter bangsa. Hal ini disebabkan oleh ukuran-ukuran dalam pendidikan tidak dikembalikan pada karakter siswa, tapi dikembalikan pada pasar. 
"Pendidikan nasional belum mampu mencerahkan bangsa ini. Pendidikan kita kehilangan nilai-nilai luhur itu". Lebih lanjut ia mengemukakan bahwa pendidikan karakter akan hancur dan akan menghilangkan aspek-aspek manusia dan kemanusiaan, karena kehilangan karakter itu sendiri”, ucapnya (Muslich, 2013: 12).

Terlepas dari berbagai problem diatas, pendidikan karakter di Indonesia mengusung semangat baru dengan optimisme yang penuh untuk membangun karakter bangsa yang bermartabat. Oleh karena itu, konsep pendidikan karakter harus mengambil posisi yang jelas, bahwa karakteristik seseorang dapat dibentuk melalui pendidikan. Pendidikan seperti apakah yang mampu membentuk karakteristik tersebut, jawaban atas pertanyaan inilah yang disebut dengan pendidikan karakter (Suyadi, 2013: 4).

Menurut UU No.20 Tahun 2003 Tentang Sistem Pendidikan Nasional pada pasal 3, yang menyebutkan bahwa pendidikan nasional berfungsi mengembangkan kemampuan dan membentuk watak serta peradaban bangsa yang bermartabat dalam rangka mencerdaskan kehidupan bangsa, bertujuan untuk berkembangnya potensi siswa agar menjadi manusia yang beriman dan bertaqwa kepada Tuhan Yang Maha Esa, berakhlak mulia, sehat, berilmu, cakap, kreatif, mandiri, dan menjadi warga negara yang demokratis serta bertanggung jawab (UU SISDIKNAS \& PP RI TH 2013). Dalam Al-Quran, Allah Swt menegaskan bahwa manusia adalah khalifah di muka bumi, sebagaimana disebutkan dalam Qs. Al Baqarah ayat 30 sebagai berikut:

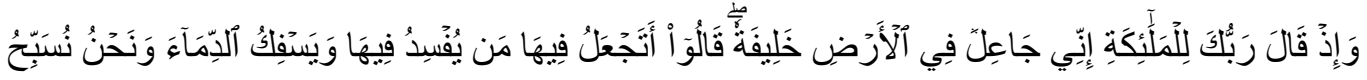

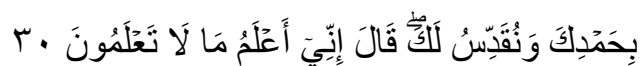

Artinya : "Ingatlah ketika Tuhanmu berfirman kepada Para Malaikat: "Sesungguhnya aku hendak menjadikan seorang khalifah di muka bumi." mereka berkata: "Mengapa Engkau hendak menjadikan (khalifah) di bumi itu orang yang akan membuat kerusakan padanya dan menumpahkan darah, Padahal Kami Senantiasa bertasbih dengan memuji Engkau dan mensucikan Engkau?" Tuhan berfirman: "Sesungguhnya aku mengetahui apa yang tidak kamu ketahui." (Depag, 2013:13). 
Pendidikan karakter merupakan keharusan yang harus diterapkan melihat kondisi disintegrasi bangsa kita yang semakin merebak, membuat harus segera dilakukan langkah preventif sejak dini, terutama di lingkungan sekolah. Sebagaimana yang dianjurkan oleh pemerintah, dalam hal ini Kementrian Pendidikan dan Kebudayaan mengenai Pengelolaan Pendidikan Karakter, Pemerintah mengharapkan lingkungan sekolah sebagai bagian terpenting dalam pendidikan karakter. Pada bagian proses pembelajaran diharapkan dapat terlaksana sebaik mungkin untuk menjadi garda terdepan dalam pendidikan karakter.

SDI Raudlatul Jannah Sidoarjo menerapkan pendidikan karakter bagi siswanya dengan berbagai program sekolah yang disesuaikan dengan kondisi sekolah yang berada di lingkungan masyarakat yang majemuk dengan sistem full day school. Sedangkan SDIT Ghilmani telah menerapkan pendidikan karakter mendahului program pemerintah pada tahun 2010 dengan sistem full day school, sekolah ini terletak dalam lingkungan pondok pesantren dan dikepalai oleh seorang Kyai. Sehingga semua kegiatan, baik kegiatan pembelajaran maupun kegiatan ekstra selalu kental dengan nuansa Islami.

Terkait dengan hal tersebut, SDI Raudlatul Jannah Sidoarjo dan SDIT Ghilmani Surabaya dijadikan sasaran lokasi dalam melakukan penelitian. Kedua lembaga pendidikan tersebut merupakan perbedaan lembaga pendidikan di lingkungan Kemenag. Hal tersebut sudah tentu bisa diperkirakan dari naungan kedua lembaga tersebut sudah berbeda. Secara umum perbedaan dari kedua lembaga tersebut adalah ciri khas dari lembaga itu dan karakter-karakter, serta model kurikulum yang diterapkan. SDI Raudlatul Jannah Sidoarjo yang berada di naungan Kemenag tentunya mempunyai beberapa pengembangan karakter inti yang sudah ada, seperti ketika peneliti melakukan survey pra-penelitian menunjukkan karakter yang dikembangkan yakni tanggung jawab atas dirinya sendiri, seperti berdoa sebelum memasuki kamar mandi. Selain itu, pengembangan 
karakter dilakukan secara terus-menerus di bawah pengawasan guru. Sedangkan di SDIT Ghilmani Surabaya karakter yang dikembangkan yakni peduli sosial yang tinggi, seperti menolong teman yang kesusahan dan saling mendukung untuk tetap bersaing dalam hal meningkatkan prestasi siswa.

Dari kedua perbedaan tersebut dapat menjadi ketertarikan tersendiri untuk dilakukan penelitian tentang strategi guru PAI dalam menanamkan nilainilai karakter. Penelitian yang dilakukan di lapangan akan lebih memperdalam terkait internalisasi nilai-nilai karakter, mulai dari merencanakan dan menganalisis karakter apa yang dikembangkan, dan penerapannya nilai-nilai karakter di kedua lembaga pendidikan tersebut.

Berangkat dari kenyataan di atas, maka peneliti berkeinginan untuk mengangkat fenomena tersebut dengan menyusun sebuah penelitian dengan judul "Strategi Guru Pendidikan Agama Islam (PAI) dalam Menanamkan Nilai-Nilai Karakter Pada Siswa (Studi Multi Kasus di SDI Raudlatul Jannah Sidoarjo dan SDIT Ghilmani Surabaya)".

\section{B. Metode Penelitian}

Adapun teknis pengumpulan data yang digunakan dalam penelitian kualitatif ini adalah :

1. Observasi atau Pengamatan

Adapun teknis pengumpulan data yang digunakan dalam penelitian ini adalah:

a) Lokasi penelitian yaitu SDI Raudlatul Jannah Sidoarjo dan SDIT Ghilmani Surabaya.

b) Subyek penelitian yaitu warga SDI Raudlatul Jannah Sidoarjo dan SDIT Ghilmani Surabaya, diantaranya: Kepala Sekolah, Guru PAI dan siswa kelas 4.

c) Obyek penelitian yaitu perihal strategi guru PAI dalam menanamkan nilainilai karakter pada siswa di SDI Raudhatul Jannah Sidoarjo dan SDIT Ghilmani Surabaya. 
2. Wawancara (Interview)

Jenis wawancara yang digunakan dalam penelitian ini adalah wawancara terstruktur. Sebelum kegiatan dimulai,peneliti membuat garis besar pokokpokok isi wawancara terlebih dahulu. Pedoman wawancara digunakan untuk memperoleh data tentang strategi guru PAI dalam menanamkan nilai-nilai karakter pada siswa di SDI Raudlatul Jannah Sidoarjo dan SDIT Ghilmani Surabaya.

3. Dokumen

Studi dokumentasi ini digunakan untuk memperoleh data tentang:

a. Latar belakang/profil SDI Raudlatul Jannah Sidoarjo dan SDIT Ghilmani Surabaya.

b. Visi dan misi SDI Raudlatul Jannah Sidoarjo dan SDIT Ghilmani Surabaya.

c. Data guru, siswwa, karyawan dan struktur organisasi SDI Raudlatul Jannah Sidoarjo dan SDIT Ghilmani Surabaya.

d. Nilai prestasi belajar siswa SDI Raudlatul Jannah Sidoarjo dan SDIT Ghilmani Surabaya.

e. Kondisi media pembelajaran SDI Raudlatul Jannah Sidoarjo dan SDIT Ghilmani Surabaya.

f. Sarana dan prasarana SDI Raudlatul Jannah Sidoarjo dan SDIT Ghilmani Surabaya.

g. Foto atau gambar proses pembelajaran SDI Raudlatul Jannah Sidoarjo dan SDIT Ghilmani Surabaya.

Teknik analisis data dalam penelitian ini menggunakan penelitian kualitatif sebagai berikut:

1. Pengumpulan Data

Pada pengumpulan data yang pertama adalah pengumpulan data yang telah diperoleh dari narasumber terkait dengan trategi guru pendidikan agama islam (PAI) dalam menanamkan nilai-nilai pendidikan karakter pada siswa di 
SDI Raudlatul Jannah Sidoarjo dan SDIT Ghilmani Surabaya dengan mencatat secara teliti dan rinci.

2. Reduksi Data

Apabila seluruh data telah terkumpul, maka untuk menganalisisnya digunakan teknik reduksi data yaitu merangkum, memilih dan memfokuskan pada hal-hal yang pokok untuk dicari pola atau tema yang berkaitan dengan strategi strategi guru pendidikan agama islam (PAI) dalam menanamkan nilai-nilai pendidikan karakter pada siswa di SDI Raudlatul Jannah Sidoarjo dan SDIT Ghilmani Surabaya.

3. Pemaparan Data

Yaitu mendeskripsikan kembali data-data yang telah direduksi dalam bentuk teks yang bersifat naratif, mengenai persepsi dan pemahaman strategi guru pendidikan agama islam (PAI) dalam menanamkan nilai-nilai pendidikan karakter pada siswa di SDI Raudlatul Jannah Sidoarjo dan SDIT Ghilmani Surabaya.

4. Penarikan Kesimpulan

Setelah data-data tersebut dipaparkan, kemudian ditarik kesimpulan dari strategi guru pendidikan agama islam (PAI) dalam menanamkan nilai-nilai pendidikan karakter pada siswa di SDI Raudlatul Jannah Sidoarjo dan SDIT Ghilmani Surabaya.

\section{Hasil dan Pembahasan}

\section{Temuan Penelitian di SDI Raudlatul Jannah Sidoarjo}

a. Nilai-nilai Karakter Yang Ditanamkan Guru Pendidikan Agama Islam (PAI) Pada Siswa

1) Dalam perencanaan penananaman nilai-nilai karakter pada siswa, guru PAI terlebih dahulu menganilis SK, KD, dan indikator materi yang akan disajikan untuk mengetahui nilai-nilai karakter yang akan di selipkan yang sesuai dengan materinya. 
2) SDI Raudlatul Jannah Sidoarjo mengembangkan karakter Student's Profile yaitu Taqwa, Visioner dan Though, Thinker dan Independent, Responsbility, Discipline, Creative-Innovative, Communicator, Pro active dan Patriotic, sehingga untuk lebih memudahkan guru PAI dalam mengembangkan karakter tersebut SDI Raudlatul Jannah sudah membekali dengan buku/Handout yang murni produk SDI Raudlatul Jannah sendiri dengan mengacu SK/KD kurikulum nasional sebagai sumber acuan dalam mengelola pembelajaran.

3) SDI Raudlatul Jannah Sidoarjo memiliki program-progam unggulan untuk menunjang proses belajar siswa, seperti leadership camp, homestay, outbond, pondok Ramadhan, talent day, pendidikan kecakapan hidup dan pendidikan lingkungan hidup.

4) Untuk mengoptimalkan penanaman nilai-nilai karakter, SDI Rudlatul Jannah bersinergi dengan orang tua dan masyarakat, agar proses pendampingan belajar siswa bisa terfasilitasi dengan baik. Seperti membentuk forum orang tua dan pelibatan orang tua dalam beberapa proses belajar putra-putrinya.

5) Penanaman nilai-nilai ke-Islaman lewat tindakan sehari-hari atau berupa pembiasaan seperti shalat dhuha, shalat dhuhur, ngaji time, dan baca tulis Al Quran.

\section{b. Strategi Guru Pendidikan Agama Islam (PAI) Dalam Menanamkan} Nilai-Nilai Karakter Pada Siswa

1) Dalam praktik pembelajarannya, Guru PAI SDI Raudlatul Jannah Sidoarjo menerapkan konsep pembelajaran yang menyenangkan menerapkan nilai-nilai keislaman, kreatifitasan, dan menyenangkan. Siswa ditempatkan sebagai pusat kegiatan pembelajaran, sehingga perkembangan akhlak siswa sangat diperhatikan.

2) Guru PAI dalam proses pembelajarannya menggunakan strategi pembelajaran CTL (Contextual Teaching And Learning) menempatkan 
siswa sebagai pusat kegiatan belajar. Siswa dilibatkan dalam proses pencarian pengetahuan dan informasi. Sehingga siswa memiliki tingkat kepercayaan diri yang tinggi dan antusias dalam mengikuti kegiatan pembelajaran, serta cakap mengolah setiap informasi yang diperoleh.

3) Guru PAI SDI Raudlatul Jannah Sidoarjo tidak menjadikan nilai-nilai yang tinggi dalam lembaran raport dan ijazah siswa sebagai hasil yang ingin dicapai, melainkan hanya memberikan siswa bekal agar cerdas mengolah informasi yang ia peroleh, serta memiliki kecakapan untuk menyelesaikan masalah-masalah kehidupan yang ia temui.

4) Prestasi yang dimiliki siswa SDI Raudlatul Jannah Sidoarjo di bidang akademik maupun non akademik. Baik atas nama individu siswa maupun sebagai sebuah lembaga, baik yang taraf lokal maupun nasional.

5) Siswa SDI Raudlatul Jannah Sidoarjo memiliki kecakapan untuk mengolah informasi yang mereka peroleh. Karena dalam proses belajarnya siswa dilibatkan dalam proses pencarian, para guru hanya memposisikan dirinya sebagai pendamping kegiatan belajar siswa.

\section{c. Proses Internalisasi Nilai-Nilai Karakter Terjadi Pada Siswa}

1) Siswa SDI Raudlatul Jannah Sidoarjo memiliki sikap dan budi pekerti yang santun, karena di sekolah ada kegiatan pembiasaan seperti kegiatan keagaamaan, dan talent day.

2) Nilai-nilai karakter diintegrasikan ke dalam buku pegangan (Handout) yang murni buatan SDI Raudlatul Jannah Sidoarjo.

3) Adanya buku penghubung antara guru dan orang tua yang berfungi memantau perkembangan nilai-nilai karakter siswa.

4) Kegiatan ikrar dan tilawah yang wajib dilakukan siswa setiap pagi sebelum memulai aktifitas belajar, baik itu kegiatan intrakurikuler ataupun ekstrakurikuler. 


\section{Temuan Penelitian di SDIT Ghilmani Surabaya}

a. Nilai-nilai Karakter Yang Ditanamkan Guru Pendidikan Agama Islam (PAI) Pada Siswa

1) Konsep sekolah yang diterapkan di SDIT Ghilmani adalah Membentuk manusia berakhlak mulia, berprestasi, disiplin, dan berbudaya lingkungan, menjadikan lingkungan di sekitar sekolah sebagai sarana belajar peserta didik. Menggunakan kebun dan segala hal yang tersedia di sekitar sekolah sebagai media belajar.

2) Mendesain tempat belajar dengan konsep terbuka sebagai upaya untuk memerdekakan siswa, memfasilitasi gaya belajar siswa, serta menjadikan suasana belajar menjadi lebih menyenangkan dan tidak membosankan.

3) Sesuai dengan visi misi SDIT Ghilmani, maka guru PAI mengembangkan nilai-nilai karakter religius, jujur, disiplin, kerja keras dan peduli sosial.

4) SDIT Ghilmani dibawah pengawasan seorang Kyai Pondok pesantren Al haromain Pujon Malang sehingga setiap kegiatan sekolah tidak luput dari kegiatan Islami.

5) SDIT Ghilmani memiliki beberapa fasilitas outbond seperti jaring labalaba, lontar tarsan, titian berjalan dan wahana outbond lainya sebagai sarana melatih ketangkasan, kecermatan, kerjasama tim, saling menghargai dan penanaman sikap baik lainya.

6) Siswa diberi tanggung jawab untuk memimpin ibadah sholat berjama'ah dengan sesama temannya. Juga dalam beberapa acara rutin yang biasa diadakan lembaga. Lewat program ini rasa kepercayaan diri serta tanggung jawab siswa tumbuh.

b. Strategi Guru Pendidikan Agama Islam (PAI) Dalam Menanamkan Nilai-Nilai Karakter Pada Siswa

1) Dalam perencanaan penananman nilai-nilai karakter pada peserta didik guru PAI terlebih dahulu menganilis SK, KD, dan indikator materi yang 
akan disajikan untuk mengetahui nilai-nilai karakter yang akan di selipkan yang sesuai dengan materinya, agar bisa selalu memberikan inovasi-inovasi guru PAI sering mengikuti Asosiasi KKG (kegiatan kerja guru).

2) Dalam kegiatan belajar mengajar guru PAI menggunakan strategi pembelajaran koopertif yakni menempatkan kebersamaan sebagai pusat kegiatan belajar siswa. Siswa dilibatkan dalam proses pencarian pengetahuan dan informasi dengan cara berkelompok.

3) Guru PAI SDIT Ghilmani memotivasi siswa agar nilai-nilai karakter bisa terwujud dalam kehidupan mereka sehari-hari, didukung dengan Materi Plus yakni materi yang wajib dibaca setiap hari di depan guru.

\section{c. Proses Internalisasi Nilai-Nilai Karakter Terjadi Pada Siswa}

1) Siswa di SDIT Ghilmani Surabaya memiliki rasa kepercayan diri yang tinggi. Hal ini ditunjukan lewat keberanian mereka tampil menjadi pengisi acara-acara yang diadakan lembaga yang dihadiri banyak orang. Rasa percaya diri penting dimiliki setiap anak agar mampu mengeluarkan segala potensi yang dimilikinya.

2) Program wajib baca setiap selasa dan kamis

3) Siswa di SDIT Ghilmani Surabaya mampu melaksanakan ibadah sholat dengan baik, membaca do'a-do'a harian dan memahami pentingnya khusu' dalam beribadah.

4) Menjadikan ajaran agama Islam sebagai tuntunan dalam bersikap, mengambil keputusan dan bertutur kata.

5) Adanya tausiyah setiap sabtu untuk para guru terutama guru PAI oleh Kyai Pondok pesantren Al Haromain dilanjutkan dengan rapat perencanaan pembelajaran satu minggu kedepan. 


\section{Simpulan}

Dalam kegiatan penelitian ini dapat diperoleh beberapa kesimpulan antara lain:

a. Nilai karakter inti yang dikembangkan guru PAI di SDI Raudlatul Jannah dikemas dalam Student Profile yang mencakup: Taqwa, Visioner dan Though, Thinker dan Independent, Responsbility, Discipline, Creative-Innovative, Communicator, Pro active dan Patriotic. Sedangkan guru PAI SDIT Ghilmani menerapakan nilainilai karakter inti adalah Religius, Jujur, Disiplin, Kerja keras, Peduli sosial.

b. Adapun strategi guru PAI dalam menanamkan nilai-nilai karakter pada pembelajaran, kedua lembaga tersebut sama-sama menerapkannya dengan cara mengintegrasikan pada indikator dan tujuan pembelajaran masing-masing pelajaran, SDI Raudlatul Jannah menggunakan metode CTL sedangkan SDIT Ghilmani menggunakan Cooperative Learning, dilanjutkan dengan mengimplementasikan pendidikan karakter pada kegiatan ekstrakurikuler (mengintegrasi dalam kehidupan sehari-hari), kemudian ke dalam program sekolah serta komunikasi kerjasama antar sekolah dengan orang tua siswa. Guru memiliki strategi khusus dengan cara mengaplikasikan perannya sebagai pendidik, pengajar, pengembang kurikulum, pembaharu, model dan teladan dalam mengintegrasikan nilai-nilai karakter ke keseluruhan mata pelajaran, ke dalam kehidupan sehari-hari, ke dalam program sekolah, dan membangun kerjasama antar sekolah dengan orang tua siswa. SDI Raudlatul Jannah lebih menekankan kepada sikap religius dan disiplin, sedangkan SDIT Ghilmani lebih menekankan kepada religius dan peduli sosial.

c. Pada proses internalisasi penanaman nilai-nilai karakter pada siswa dengan cara mengembangkan aspek kognitif, afektif dan psikomotorik siswa.

\section{Daftar Rujukan}

Departemen Agama RI. (1989). Al-Quran dan Terjemah. Surabaya: Mahkota. 
Mulyasa. (2009). Menjadi Guru Profesional Menciptakan Pembelajaran Kreatif dan Menyenangkan. Bandung: Remaja Rosdakarya.

Mulyasa. (2007). Kurikulum Tingkat Satuan Pendidikan. Bandung: Remaja Rosdakarya.

Muslich, Masnur. (2013). Pendidikan Karakter Menjawab Tantangan Krisis Multidimensional. Jakarta: PT Bumi Aksara.

Permadi dkk. (2010). The Smiling Teacher. Bandung: Nuansa Mulia.

Ramayulis. (2010). Ilmu Pendidikan Islam. Jakarta. Kalam Mulia.

Samani, Muchlas dan Hariyanto. (2011). Konsep dan Model Pendidikan Karakter. Bandung: PT Remaja Rosdakarya.

Suyadi. (2013). Strategi Pembelajaran Pendidikan Krakter. Bandung: PT Remaja Rosdakarya.

UNDANG - UNDANG REPUBLIK INDONESIA NOMOR 20 TAHUN 2003 tentang SISDIKNAS \& PERATURAN PEMERINTAH RI TAHUN 2013 tentang STANDAR NASIONAL PENDIDIKAN serta WAJIB BELAJAR. 2014. Bandung: Citra Umbara. 